\title{
Tornado activity in Greece within the 20th century
}

\section{P. T. Nastos and J. T. Matsangouras}

Laboratory of Climatology and Atmospheric Environment, Faculty of Geology and Geoenvironment, University of Athens, Panepistimiopolis, 15784 Athens, Greece

Received: 19 February 2010 - Revised: 13 March 2010 - Accepted: 31 March 2010 - Published: 7 July 2010

\begin{abstract}
Tornado activity is associated with extreme convective weather which can cause extended damage and even in some cases the loss of life. The complex inland terrain of Greece along with the Ionian Sea at the west and the Aegean Sea at the east appear to be a favorable area for fury phenomena such as tornadoes, waterspouts and funnel clouds.

In this study, the spatial and temporal variability of tornado activity in Greece for the period 1900-1999 are presented. The spatial distribution of tornadoes, waterspouts and funnel clouds reveals the vulnerability of specific geographical areas, such as the west Greece and the south Aegean Sea. As far as the intra annual variability is concerned, the maximum of tornado activity dominates within the cold period of the year (October-March) while according to the daily distribution, tornadoes happen frequently during the warm hours of the day. It is remarkable to mention that in Greece, within the 20th century, the tornado activity caused the loss of 4 lifes, the injury of 40 people and numerous damages on human constructions and cultivations.
\end{abstract}

\section{Introduction}

Tornadoes are extreme phenomena associated with severe convective storms. Although several nowcasting and prognostic tools are available nowadays, tornadoes forecasting appear to be still impossible in long term periods. Tornado forecast research is in progress in order to understand and interpret the development of such a furious event. Zavolgenskiy and Rutkevich (2009) tried to develop an analytical model of convection in a thick horizontal cloud layer with free upper and lower boundaries and they found that the con- vection in these conditions can be a localized phenomenon. The region where the convection takes place is associated with the largest instability gradients and the cloud rotation, which should be sufficiently strong.

Tornadoes have been recorded all over the world with significant impacts (Fujita, 1973), while a lot of research has been carried out during the last two decades indicating the occurrence of tornadoes in many European countries (Dessens, 1984; Dessens and Snow, 1987; Paul, 1999; Reynolds, 1999; Dotzek, 2001; Holzer, 2001; Sioutas, 2003; Matsangouras and Nastos, 2010). Greece, at the eastern part of the Mediterranean Sea with long shores, shallow waters near coastal areas and complex geomorphology, appears to be a favorable region for the tornado development. However, there are only limited references in academic literature concerning a thorough and comprehensive research in the tornado occurrence in Greece. Only descriptions of individual research on waterspout case studies (Kyriazopoulos and Livadas, 1975; Kanellopoulou, 1977; Flocas, 1992; Sioutas 2002; Keul 2003) or "fish" rain phenomena (Livadas, 1954) have been presented. Furthermore, Sioutas (2003) found 17 tornado cases with scattered distribution in Greece during the period 1910-1999, resulting in an average of two tornadoes per decade. According to this research, there is a tendency for tornado development generally over the west and south coastal areas.

The goal of this study is to present the spatial and temporal variability of tornadoes, waterspouts and funnel clouds within the twentieth century based on the research of Greek literature, local and national newspapers, administration records and meteorological reports from the Hellenic National Meteorological Service (HNMS).

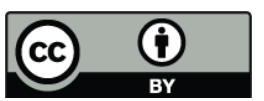

Correspondence to: P. T. Nastos

(nastos@geol.uoa.gr)

Published by Copernicus Publications on behalf of the European Geosciences Union. 

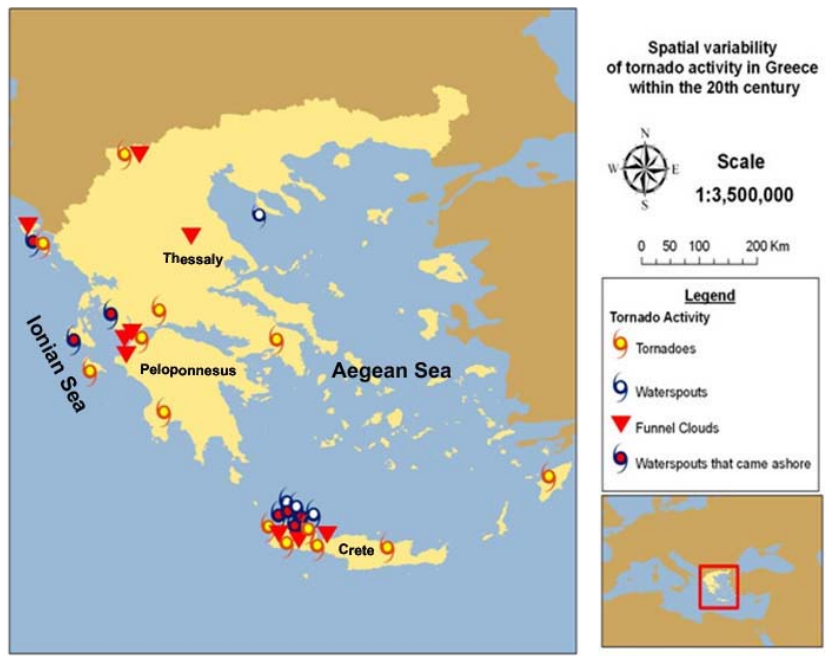

Fig. 1. Spatial variability of tornado activity in Greece within the 20th century.

\section{Historical record of the tornado activity in Greece}

A total number of 33 tornadoes, waterspouts and funnel clouds have been found within the twentieth century, based on the research of Greek literature, local and national newspapers, local administrative and personal records via internet network and meteorological reports from the Hellenic National Meteorological Service (HNMS). It is worthy to remark that the number of 33 cases seems to be small with respect to the examined period, due to limited sources of information, mainly concerning the first half of the 20th century. This database is assumed incomplete and more likely biased, as more cases are likely to be found in the future. In this point, it should be noted that search for historical tornadoes events could be characterized as a continuous work in progress as historical reviews contribute to obtain significant climatological information (Paul, 1999; Tyrrell, 2001). A historical database contributes to climatology in order to define the favorable weather conditions for the onset of tornadoes.

Our findings show that the 33 events occurred in 29 days during the period from 1900 to 1999 and 13( 39\%) events were characterized as tornadoes, $11(\sim 33 \%)$ as waterspouts (7 of them came ashore and caused several damage) and $9(\sim 27 \%)$ as funnel clouds (FC). The funnel clouds were retrieved from the meteorological reports of several weather stations of the HNMS network, where FC were reported as present weather on synoptic (SYNOP) reports. The 33 tornado events in Greece during the period 1900-1999 correspond to an average number of 3 tornadoes per decade.

\subsection{Spatial distribution of tornado activity}

Based on this historical database the spatial distribution reveals a tendency for tornado development in west and south

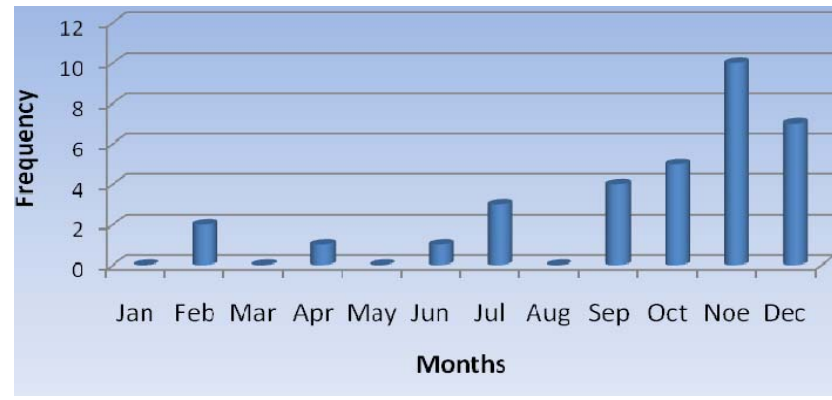

Fig. 2. Monthly variability of tornado activity in Greece within the 20th century.

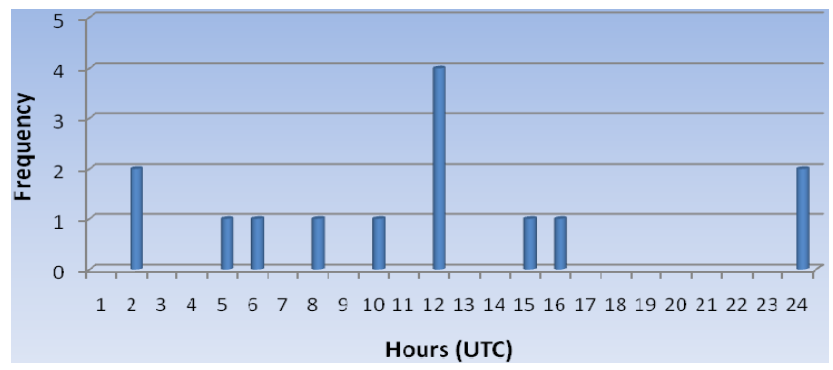

Fig. 3. Hourly variability of tornado activity in Greece within the 20th century.

coastal areas of Greece, a conclusion which is in agreement with Sioutas (2003) findings.

The complex inland terrain of Greece along with the Ionian Sea at the west and the Aegean Sea at the east appear to be a favorable area for fury phenomena such as tornado, waterspouts and funnel clouds. More specifically, northwest Peloponnesus and north parts of Crete Island (south Aegean Sea) seemed to be the favorable areas for tornado development. The remarkable tornado activity at western Crete in contrast to the eastern parts of the island (retrieved from records of local authorities), revealed an area with favorable conditions for tornado development. This is confirmed by a new research of the authors, which is in progress, studying the tornado variability for the period 2000-2010, where, numerous tornado events (especially waterspouts) were observed over western and northern parts of central Crete and not over eastern parts. The spatial distribution of tornadoes, waterspouts and funnel clouds is depicted in Fig. 1. According to the information from local authorities, 18 out of 33 cases are related to significant damage both in urban and agriculture areas. Tornado activity is associated with extreme convective weather causing extended damage and even more in some cases the loss of life. During the period 19001999 , the tornado activity caused 4 fatalities, 40 people were injured and several damages occurred leaving many people homeless. 


\subsection{Temporal variability of tornado activity}

Based on the constructed historical database, the monthly variability reveals a tornado tendency of occurrence during autumn and winter while the maximum appears in November and December followed by October and September (Fig. 2).

The most remarkably events recorded within the twentieth century appeared in autumn and concern: the killer waterspout that came ashore and hit Astakos in Aitoloakarnania (a coastal urban area at west Greece) on 18 October 1934, the "fish-rain" event where the tornado activity sucked fishes from the nearest lakes at Alona village in Florina prefecture (NW Greece, nearby Prespa lakes) during 13-15 October 1951 (Livadas, 1954) and the coming ashore waterspout, which caused several damage in Corfu on 1 September 1973 (Kanellopoullou, 1977).

The hourly variability of tornado frequency in Greece during the examined period shows that tornado development mostly happens between 05:00 and 16:00 UTC (Fig. 3). This conclusion is based on the $30 \%$ of the total tornado events from which the exact time of tornado occurrence was known.

\section{Conclusions}

Tornado activity (tornadoes, waterspouts and funnel clouds) was presented based on spatial and temporal variability in Greece within the 20th century. Whirlwind phenomena (33 known/registered events occurred in 29 days) caused the loss of 4 lifes, the injury of 40 people and numerous damage on human constructions and cultivations during the last 100 years. The constructed historical database is a research product derived from the Greek literature, local and national newspapers, administration records and meteorological reports from the Hellenic National Meteorological Service.

The spatial variability reveals a tendency of tornado activity to occur mainly over the west and south coastal areas of Greece, especially over northwest Peloponnesus and north Crete Island. The temporal variability depicted that, tornado activity appears mainly within the cold period of the year (autumn and winter) with maxima in November and December followed by October and September. According to the daily distribution, tornadoes mostly happen between 05:00 and 16:00 UTC.
The constructed historical tornado database is considered incomplete as more cases are likely to be found in the future and a search for historical tornado activity in Greece is characterized as a continuous work in progress.

Edited by: M. C. Llasat

Reviewed by: one anonymous referee

\section{References}

Dessens, J. and Snow, J. T.: Tornadoes in France, Weather Forecast., 4, 110-132, 1987.

Dessens, J.: Les Trombes en France, Climatologie et Caracteristiques Physiques, Lannemezan, France, 1984.

Dotzek, N.: Tornadoes in Germany, Atmos. Res., 56, 233-251, 2001.

Fujita, T. T.: Tornadoes around the world, Weatherwise, 26, 56-83, 1973.

Holzer, A. M.: Tornado climatology of Austria, Atmos. Res., 56, 203-211, 2001.

Kanellopoulou, H.: The waterspout of 1st September 1973 in Corfu, Bull. Greek Met. Soc., 5(5), 41-50, 1977 (in Greek).

Keul, A. G.: A series of waterspouts off the Cretan north coast 5th September 2002, J. Meteorol., 28(275), 15-26, 2003.

Kyriazopoulos, V. and Livadas, G.: Practical Meteorology, 296298, Univ. Thess, 1975.

Livadas, G.: Fish rain in western Macedonia, Meteorologika, No. 2, Publ. Met. Inst. Univ. Thess., Thessaloniki, 1954.

Matsangouras, J. T. and Nastos, P. T.: The 27 July 2002 tornado event in Athens, Greece, Adv. Sci. Res., 4, 9-13, 2010.

Paul, J. F.: An inventory of tornadoes in France, Weather, 54, $217-$ 219, 1999.

Reynolds, D. J.: European tornado climatology 1960-1989, J. Meteorol., 24, 376-403, 1999.

Sioutas, M. V.: Damaging tornadoes in Greece: July and September 2001, J. Meteorol., 27, 17-22, 2002.

Sioutas, M. V.: Tornadoes and waterspouts in Greece, Atmos. Res., 67-68, 645-656, 2003.

Tyrrell, J.: Tornadoes in Ireland: an historical and empirical approach, Atmos. Res., 56, 281-290, 2001.

Zavolgenskiy, M. V. and Rutkevich, P. B.: Tornado funnel-shaped cloud as convection in a cloudy layer, Adv. Sci. Res., 3, 17-21, 2009. 